\title{
The Bouzouki's Signifiers and Significance Through the Zeibekiko Dance Song: "Evdokia's Zeibekiko"
}

\author{
Evangelos Saragatsis \\ Musician, Secondary Education Teacher, Holder Of Postgraduate Diploma \\ Ifigeneia Vamvakidou \\ Professor at the University of Western Macedonia, Greece
}

Doi: 10.19044/esj.2017.v13n35p125 URL:http://dx.doi.org/10.19044/esj.2017.v13n35p125

\begin{abstract}
The objective of this study is to identify the signifiers and significance of the Zeibekiko dance, and those of the bouzouki itself, to a further extent, as they emerge through research conducted in the relevant literature, and which is anchored to those signifiers, as they are highlighted through their presence in material that is obtained from movies. The semiotic analysis of the film "Evdokia", by A. Damianos (1971), is the research method that is followed.

In this context, the main focus is placed on the episode/scene, where Evdokia's Zeibekiko is displayed on stage. This 'polytropic' (polymodal) material that consists of listening to, viewing, playing music, and dancing encompasses a large variety of musicological and gender signifiers that refer to the specific era. The model followed is that of Greimas (1996), as it was used by Lagopoulos \& Boklund-Lagopoulou (2016), and Christodoulou (2012), in order to point out those characteristic features that are expressed by the bouzouki, as a musical instrument, through a representative sample of the zeibekiko dance, as it is illustrated in the homonymous film.

The analysis of images, as well as of the language message, lead to the emergence of codes, such as the one referring to the gender, and also the symbolic, value, and social codes, and it is found that all these codes agree with the introductory literature research conducted on the zeibekiko dance and the bouzouki. Based on the combination of these approaches to the analysis performed, a number of elements can be clearly identified, such as the dancer's masculinity, the loneliness that characterizes the dance, the values adhered to and the respect shown to the codes of honor, and all these elements confirm the initial literature research conducted on the zeibekiko dance, and by extent, the fact that the bouzouki expresses all the above characteristics.
\end{abstract}


Keywords: Bouzouki, semiotic analysis, Evdokia, zeibekiko

\section{Introduction}

Undoubtedly, sound and rhythm are two elements that are inextricable linked to human life (Leousi, 2003:10). On top of that, music, as a form of art, is characterized by its ability to satisfy the human need for expressing the emotions and different mental conditions through the use of sound.

The research question that is going to be addressed through this paper, refers to the characteristics, either stereotypical or not, of the zeibekiko dance, and the bouzouki itself, by further extent, as they have been recorded in the relevant literature.

Therefore, a study is conducted on the Evdokia's Zeibekiko, which is an instrumental song without any lyrics, written by M. Loizos, as it is presented through the film "Evdokia", by A. Damianos. This means that the subject of the study is a traditional male dance, although its name refers to a woman, which is an oxymoron, in terms of language, and causes a problem, as it contradictory to tradition.

"Zeibekiko" is a Greek folk dance. Its name is derived from the Islamized Greek population of the "Zeibeks" (Baud-Bovy, 1984:46-47 \& Dragoumis, 1984:58). It is reported that it was spread to the Greek mainland urban centers during the late $19^{\text {th }}$ century.

Its emergence, however, dates back to the late $17^{\text {th }}$ century, in conurbations such as Istanbul (Constantinople) and Izmir (Smyrna) (Tyrovolas, 2003:132).

Evliya Celebi reports that it used to be danced in local festivities that took place in Manisa (Magnesia) and Aidyn (Aidinion) (Palis, 1941:231). Although it was originally a dance of two persons facing each other and carrying weapons, it evolved into a "one-person improvisational male dance" (Tyrovolas, 1994:108).

This one-person facing dance (antikristos) is used by the film director as a warlike flirtation between the two leading actors, as well as a way to show the conflict between tradition and modernity.

Zeibekiko is defined as a form of the rebetiko dance at least during the 1850-1953 period in terms of its social dimension. From 1953 to 1980, the later developments and transformations of the Greek society bring zeibekiko forward as a folk dance. From 1980 onwards, it has been defined as a Pan-Hellenic dance, the development and evolution of which follows the Greek urban folk music tradition (Tyrovolas, 2003:134).

In this line, the fact should be stressed that culture plays a linking role between the members of a human community. It also defines the boundaries, 
as well as the specific difference, that makes this community unique, and associates it with particular cultural characteristics and uninterrupted selfawareness. Consequently, any reference to the Modern Greek culture specifically refers to a culture that uses the Greek language as a means of language expression. Nevertheless, it could be argued that culture is omnipresent in any communication system and context that has been developed by the community in question (e.g. social organization, economic relations, kinship systems, customary life, rituals, etc.); its most comprehensive expression, however, can be identified in the language communication systems, i.e. in oral speech and written texts. It is worth taking note of this aspect in terms of the methodology followed, since it is associated with addressing a fundamental theoretical issue, which is no other than that of the sources. In order for a systematic study of a particular phenomenon to be undertaken, such as culture, which is widespread throughout the expressions of various forms of material and intellectual activity that take place within a society, it is necessary to search for a field that is readily identifiable, and also valid and characteristic of the phenomenon (Kapsomenos, 2005:1-2).

According to D. Stathakopoulos (2013), the bouzouki is made in the Ancient Greek Dorian scale; the "masculine" one, as Plato used to call it. That is also the reason why the rebetiko songs are heavy songs for males, and are danced exclusively by males. The bouzouki is a later development of the ancient Greek "pandouris", which was renamed to "tambouras" in the Byzantine times, and to bouzouki (Bozuk=broken) during the Turkish occupation period. The modern-day bouzouki is made in Dorian mode D scale, and that is why all the modes of the rebetiko music are derived from the Dorian mode D scale. Another thing that could be argued is that the bouzouki is the musical instrument that Plato recommends young people to listen to, in order for them to be entertained in a masculine manner. Rebetiko music or folk music is basically the form of ancient Greek music that is recommended by Plato to young people, in his work "The Republic" (Politeia).

\section{Methodology}

Five stop-motion scenes have been selected from the scene that comprises the research material, through the assistance of a special software program (VLC media player). An analysis is attempted of the images and the language text that accompanies them, as well as an identification of the codes, according to semiotic theory. After that, the style of the images is illustrated, followed by an analysis of the language text. Finally, an investigation takes place of the characteristic elements that are reflected in the bouzouki, as a musical instrument, by utilizing a representative sample of 
the zeibekiko dance, as it is displayed in the film. In order to carry out the study, various methodological tools were borrowed from the field of semiotic analysis, combined with the adoption of the Greimas model (1996), as it was used by Lagopoulos \& Boklund-Lagopoulou (2016), and Christodoulou (2012).

The key features of the zeibekiko dance, albeit any differences in its origin are structured into a typology (Tyrovolas, 1992:129).

Zeibekiko is illustrated as a folk improvisational dance, in 9/8 rhythm, originating possibly from Asia Minor, and is danced by one person, according to his personal taste. Special emphasis is placed on how it is danced, referring to a free-improvisational style (Moisiadis, 1986:85). The loneliness that characterizes the dance is also highlighted, through which, it is possible for the person to express his emotions, such as loneliness, excitement and distress, masculinity, and so on (Petridis, 1980:57).

In all the accounts that chiefly describe the characteristics of the dance the key emphasis is placed on the elements of individuality, solitude/loneliness, masculinity, and the peculiar-autonomous character that is promoted through the zeibekiko dance. An important key point that is identified in these descriptions is the frequency of the following phrase: the dancer(s) of the zeibekiko dance, which indicates the dominant figure of the male, and highlights an additional characteristic of this dance: its strong link to the male gender (Mazaraki, 1985:49).

The presence of the bouzouki, as a Greek musical instrument, just like the instruments of the tambouras family with a long "sleeve" and a small sound box, has been recorded in the area of Greece from a very early time (Anogeianakis, 1991:207-210).

\section{Research material}

The selection criteria for this specific cinema movie, as research material, refer to highlighting the bouzouki's role as a key musical instrument for performing a representative music track of the zeibekiko dance.

This particular music track is one of the subjects most widely taught to the students of the musical schools of Greece. The cinema movie in question meets the initial requirement, since its creator introduced the zeibekiko dance in his movie, and placed it in a prominent position in the film's plot. Thus, in Evdokia, the zeibekiko dance constitutes the event that induces the contact between the two leading actors, and builds the sequence of the plot.

In addition to the above criterion, however, special emphasis was placed on the social setting of the movie, which is interwoven gradually and in parallel to the action of the characters impersonated by the leading actors. 
More specifically, the plot of Evdokia offers the opportunity to highlight the social issue of honor versus disgrace, which is closely linked to the social construction of the gender.

In terms of methodology, a presentation of the movie takes place, along with a deconstruction of the images/episodes on a level of manifestation and definition of codes. The analysis conducted includes the prevailing/dominant code, which is illustrated in the first line of image analysis, as well as the object code, the space code, the style of the images, and the content and subject of the image.

Specifically: b1) in the dominant code, reference is made to the code that prevails, without dismissing the presence of other codes as well, which are, however, considered to be secondary in this assignment, b2) in the object code, the objects are recorded, which are illustrated in the pictures (tavern, chairs, peaked cap, etc.), b3) in the space code, where a recording of the space typology is illustrated (indoor/outdoor), b4) in the style of the image.

Next, a language analysis of the scene follows, in terms of the semiotic codes, in order to explore the relationship between the signifiers that are reflected in the bouzouki, as a musical instrument, through a representative sample of the zeibekiko dance.

The research process is founded on the method that refers to utilizing the analysis model used by Christodoulou on language and image (2003, 2007, 2012), with some adaptations applied to the model, in order to meet the needs of this research study. The methodology used was founded on two key approaches, i.e. the analysis of the images according to the model of Barthes (1988 \& 2007), and the analysis of the text according to the model of Greimas (1966 \& 1968).

The analysis of the text was based on the model used by Greimas. During the first stage of text analysis conducted according to the model of Greimas, it is essential to identify the groups of words that share a common semiotic content. These groups are called "isotopies" (Boklund-Lagopoulou, $1982 \&$ 2016). Their presence within the text ensures its consistency with the concept and the topic (Christodoulou, 2003:59). A word is possible to be included in more than one isotopies. Then, the isotopies are organized according to the criterion of the semiotic element that is common to the words contained in each one of them. In this way, structured sets are formed, as well as semiotic codes, and the relationships that exist among them are highlighted (Boklund-Lagopoulou, 1982:150).

The analysis of the images and titles of the chapters/sections was also based on the study conducted by Barthes on the image and the word message, i.e. the text that accompanies the image. The word message will be either anchored to the image message, or it will be supplementary to it. In the 
first case, it confirms what is seen and perceived by the viewer, while in the second case, its role is to cover the missing elements of the image (Chalavelaki, 2010:152).

According to Barthes, the full interpretation of the photograph entails the perception of three types of messages; that is the language message, and both the codified and non-codified visual messages (Barthes, 2007).

Barthes reverses the order of the visual messages, and believes that the non-codified one, as a carrier of literal meaning, serves as the basis, upon which the codified, or otherwise, symbolic message, is based. Therefore, on a literal level, the "manifested" image (as he calls it) can be found, which refers to the reproduction or representation of the factuality of an object, an event, or a situation. On a symbolic level, a connotation is identified in the form of associations caused by the image, with regard to the multiple possible variations of the meaning. The reception of the symbolic message is associated with the national, cultural, and aesthetic knowledge possessed by each individual reader (Barthes, 2007).

\section{Semiotic documentation of the cinematographic material}

\begin{tabular}{|c|c|c|c|}
\hline Film Title & $\begin{array}{c}\text { Evdokia/female name } \\
\text { Means the female } \\
\text { that has a good } \\
\text { opinion }\end{array}$ & Duration & 97 minutes \\
\hline Production Year & 1971 & Producer & $\begin{array}{c}\text { Katamor-Alexis } \\
\text { Damianos }\end{array}$ \\
\hline Scriptwriter/Director & Alexis Damianos & Music Composer & Manos Loizos \\
\hline Leading actors: & $\begin{array}{c}\text { Maria Vasileiou, } \\
\text { Giorgos Koutouzis }\end{array}$ & Genre & Erotic drama \\
\hline
\end{tabular}

Marker: Nowadays, when someone refers to "Evdokia's Zeibekiko", he/she implies the orchestral track written by Manos Loizos. This zeibekiko song, which is widely regarded as the top zeibekiko dance in history, was written by Loizos on the material of the movie "Evdokia" that was given to him by the director of the film, Alexis Damianos. The song was based on the scene of a neighborhood tavern, where a soldier stands up and dances zeibekiko with passion, boldness, and religious reverence, looking beautiful Evdokia straight into the eye. Despite the fact that she is accompanied by three grim-looking men, she also gets carried away by the rhythm of the music, claps her hands, stares at him insatiably, and monologues about the passion that will inevitably follow: "Oh, Virgin Mary!".

The musical frame: Loizos, who had written music for films again in the past, had a look at the material during the filming, which took two days, and which included numerous shots of the scenery, the soldier's dance, and Evdokia's laughter, in order to enter the viewer into the tavern. During the 
filming, the dance had been adapted to a song by Markos Vamvakaris. According to the most widespread version of the story, this song was "Your eyelids shine". However, Giorgos Koutouzis, who was the leading actor of the scene, and played the role of the soldier, had said in one of his interviews that the song was "Naughty".

Musical happenings: Loizos writes "Evdokia's zeibekiko" based on this scene. The notes of the song are first heard in the composer's home, in the presence of the director, Alexis Damianos, and with the old rebetis, Giorgos Mouflouzelis, playing the tzouras. The same tzouras is later requested by Loizos, in order for it to play in the recording of the track. As Thanasis Polykandriotis has reported, Loizos insisted on the song being played with it, although it used to go out of tune after the first few notes. Finally, the composition is recorded piece-by-piece, in order for the out-oftune tzouras to also play its part in it. Although the film participated in the Thessaloniki International Film Festival in that year (1971), it failed to win the music award. Loizos, however, includes the song, with new orchestration, in the record "Na chame ti na chame" (1972), and "Zeibekiko" begins to gain its own, "autonomous" existence, separately from the film. The track is left without any lyrics, although, according what is narrated by Lefteris Papadopoulos, Loizos asked him to write the lyrics, but he refused to do so when he listened to the music. He said that the song did not need any lyrics, since it spoke for itself. During the music played in the film, the voice and laughter that is heard is of Eleni Roda, who dubbed the leading actress, Maria Vasileiou, because she did not speak fluent Greek.

Script: The plot is about a prostitute and a sergeant in Thrace, who try to live love, while they have to deal with the taboos of the society, as well as personal entanglements and obsessions. The social setting of the Greek countryside in the 1970s seems to have a destructive effect on the love between the young whore and the soldier (Valoukos, 1998:113-114).

Another important aspect that should be emphasized is the time that the movie was produced. At that specific time, the Greek cinema industry was not characterized by a particularly positive outlook (Sotiropoulou, 1984:91). Over the period of the postwar reconstruction that took place in capitalistic Greece, and the capitalistic growth during the 1950s and 1960s, major shifts were noted in the structure of the social classes that composed the population. Namely, new branches of the bourgeoisie emerged during the German Occupation period, as a result of their involvement in "black market" and other activities. Additionally, the class of public servants was grown further, and significant portions of the rural populations moved to the urban centers, with a part of them becoming "proletarized". At the same time, young people originating from the working classes, and particularly from the segments that accumulated riches during the German Occupation 
period (the "black market" etc. and then UNRRA) moved to the urban centers, making up new dynamic bourgeois classes, such as self-employed scientists (physicians, lawyers, engineers, etc.), as well as traders, craftsmen, etc. The capitalistic growth that took place during the 1950s, and primarily in the 1960s, and which preceded the junta of 1967, gave a boost to the middle classes of urban areas. This boost was further supported by the "quid pro quo" (antiparochi) policy in land building, which was adopted by the junta regime (Zolotas, 1997).

The fictional context: According to Roussos (2016), in 1967, when the scriptwriter, Alexis Damianos, wrote the film's script, he wanted to associate the title of the film with his mother's name, as well as the female leading actress; the original title, however, was "The prostitute and the soldier". The scriptwriter identified the suitable leading actress in the face of Maria Vasileiou, when she met her in London. Damianos provided guidance to the two amateur actors on a daily basis, as a result of his catalytic decision not to work with professionals, and finally, the movie was filmed in English.

The cinematographic context: The film "Evdokia", by Alexis Damianos, was first released in September 1971. On the $28^{\text {th }}$ of March 1971, in Cannes, it was awarded the prize of the French Cineclubs, and Maria Vasileiou won the award for best actress for her role in the movie in the Thessaloniki International Film Festival. The film of Alexis Damianos was honored by the Pan-Hellenic Film Critics Association (P.E.K.K.) in 1985, as the most influential Greek film of all times.

Political context: However, after the release, the director was imprisoned for six years. He was sentenced, on the grounds that he offended the values of the Greek army. It took Alexis Damianos twenty years to film his next movie.

In 1971, Loizos composes the music and the familiar Zeibekiko, in D Minor, for the film "Evdokia"; a film that is a highly straightforward reflection of Greece of that era. Manos Loizos will be captured and held in detention by the police numerous times. Finally, the fall of the Junta will become the starting point for the most creative period of his life (Gionis, 2014:198-201).

\section{Analysis of images taken from "Evdokia's Zeibekiko"}

The selected episode/scene refers to the part of movie from 4:15 to 8:00. In specific, an analysis of five stop-motion scenes takes place, which were taken by using a special software program (VLC media player).

The methodology tools that were employed in the semiotic analysis and the model of Greimas (1996), as they were implemented by Lagopoulos \& Boklund-Lagopoulou (1982 \&2016), and Christodoulou (2012), have provided support to the research attempt. 
Evdokia, who is the leading actress of the movie, appears in the scene, along with her friend Maria, while the latter does some fortune telling for her over a cup of coffee, and cautions her that she will meet a new person, and that she should also keep an open eye for a cross and a crown. This is followed by the scene, in which the sergeant-leading actor of the movie is dancing "Evdokia's Zeibekiko", with the shadow from the sergeant's body forming the symbol of the cross in the foreground. The scene is taking place in a tavern of that era, in which where there are males, and only one female, Evdokia. Evdokia challenges the "common ethics" by daring to dance with the sergeant just for a couple of seconds, clapping her hands for him; the sergeant's response is also provocative, as he is buying Evdokia a drink, while it is clear that the latter is accompanied. Evdokia's company does not like this gesture, and is throwing the wine down on the floor. All this triggers a fight, with the sergeant being evidently outnumbered.

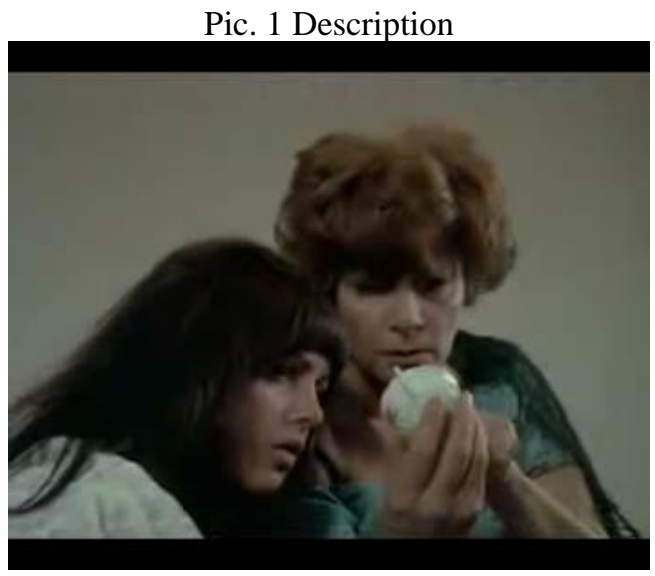

In the first picture (pic. 1), the leading actress is illustrated in a profile position in the foreground, which implies an internal narrative look, and the same also applies to her friend, as she touches the coffee cup.

Picture 1 analysis

Gender code: females with a focused look

Object code: a coffee cup that signifies destiny and fate

Space code: indoor/home

Style: realistic image

Signifiers: gender (2 females), space (home) 


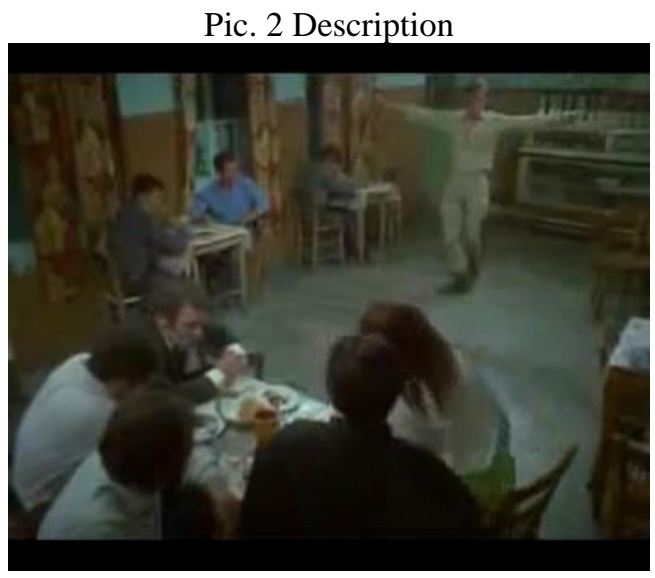

In the second picture (pic. 2), the sergeant-leading actor appears to be dancing Evdokia's Zeibekiko inside a tavern, while he is being watched by the regulars, with Evdokia being one of them.

Picture 2 analysis

Symbolic code: dance/cross symbol

Object code: tables/chairs

Space code: indoor/tavern

Style: realistic image

Signifiers: symbolic (dance/cross), gender (only one female among males)

Pic. 3 Description

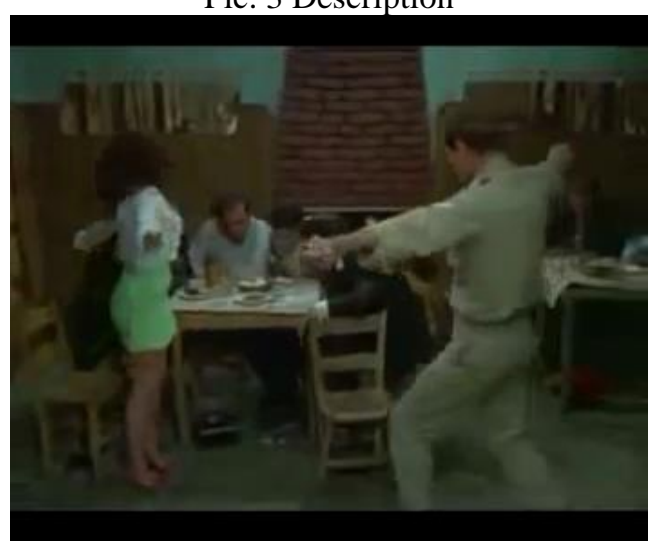

In the third picture (pic. 3), the leading actors appear to be dancing Evdokia's Zeibekiko inside a tavern.

Picture 3 analysis

Value code: dancing with an accompanied female

Object code: tables/chairs

Space code: indoor/tavern

Style: realistic image

Signifiers: value (dancing with an accompanied female), gender/social (a female is dancing a male dance, among males) 


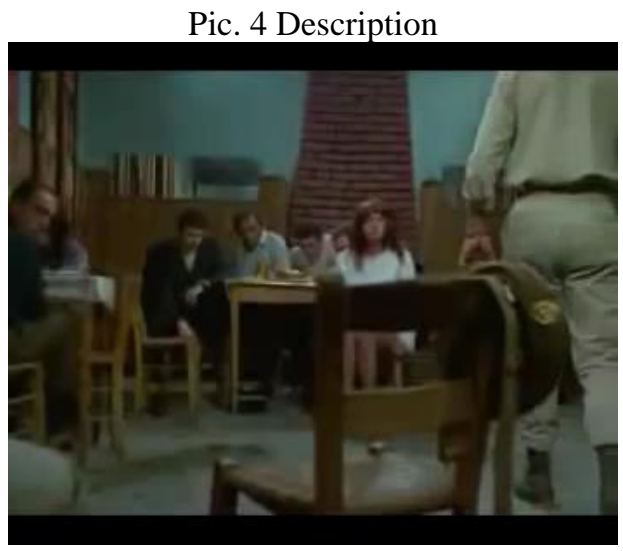

In the fourth picture (pic. 4), the sergeant's crowned peaked cap can be seen in the foreground, as it is hung at a chair's back, while the sergeant is standing up and having eye contact with Evdokia and her company.

Picture 4 analysis

Social/Symbolic code: crowned peaked cap (symbolizes the regime of that era-crowned democracy)

Object code: tables/chairs

Space code: indoor/tavern

Style: realistic image

Signifiers: social/symbolic (peaked cap/crown)

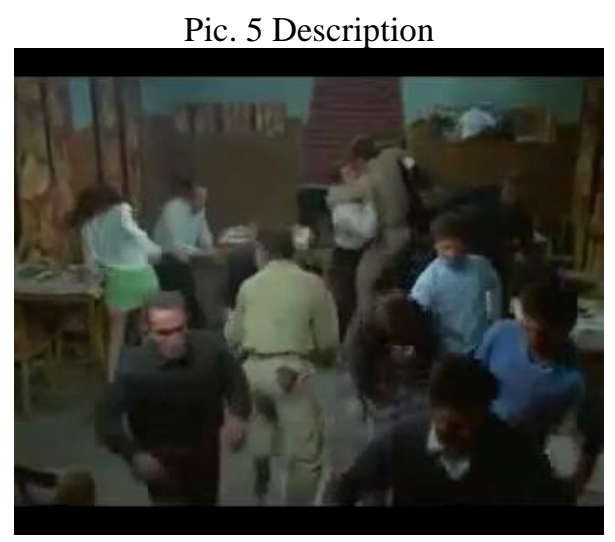

In the fifth picture (pic. 5), a full-scale fight appears to be taking place in the tavern, where the sergeant has grabbed from the throat two men from Evdokia's company, and the other customers of the tavern are leaving the place in haste.

Picture 5 analysis

Social/Value code: masculinity/insult

Object code: tables/chairs

Space code: indoor/tavern

Style: realistic image

Signifiers: civil war (masculinity/insult) 


\section{Graphical representation of the image codes}

According to the analysis of the pictures taken from "Evdokia's Zeibekiko", the resulting dominant codes are the social and gender ones, with a total frequency of $54.54 \%$, followed by the symbolic and value codes, with a total frequency of $36.36 \%$, and the space code, with a frequency of $9.09 \%$. Next, there is a table with the relative frequencies, and a graphical representation

\begin{tabular}{cc}
\hline Line labels & Frequency Sum \\
\hline Social & $27.27 \%$ \\
Gender & $27.27 \%$ \\
Value & $18.18 \%$ \\
Symbolic & $18.18 \%$ \\
Spatial & $9.09 \%$ \\
\hline Overall sum & $\mathbf{1 0 0 . 0 0 \%}$ \\
\hline
\end{tabular}

According to Bourdieu (2006, 2007), the social construction of the gender is a function of these categories, which generate, define, organize, and correlate the distinct characteristics of the male and the female, in biologic, anatomic, body, behavioral, and spatial terms. In this way, they symbolically define and validate the visible - i.e. the symbolically recognized and recognizable - differences between the male and the female, which also compose their distinct identities.

This construction, however, which is characterized itself by arbitrariness, as well as being a product and a process that results from social hierarchy, in order to be born and maintained, requires a continuous and ongoing collective social processing to take place, with regard to the semantic/semiotic and practical structuring of these divisions. Therefore, it presupposes a system of social relations that is semantically and practically organized in genres, according to the principles of the division; within this system, the subjects are socialized, and incorporate internally these principles, as well as apply them, in turn, to their social realm. This task of symbolic construction (should) also be oral (name-giving), as it generates illustrations about the objective world and about the subject itself and its body, and objectifies these illustrations within the social realm. It should be noted that these illustrations serve as systems that delimit the possibilities, and aim to impose a differentiated definition of the bodies, as well as its symbolically validated use, and rule out any possibility that is ascribed to the other gender.

Therefore, the role of the historically structured system of relations is labeled, at least in functional terms, as a symbolic device, which hatches relatively and differentially defined mental and physical predispositions 
towards the relatively opposed genders, i.e. the male and the female. This form of socialization that refers to the gender, and which is both mental and physical, transforms the body (as well as the subject itself as a whole) into a gender-related reality, and a carrier of the internally incorporated engendered and engendering principles of consideration and division of the social realm, both on a semantic and a practical level. In this way, through socialization, the subjects are engendered, by incorporating internally their genderstructured mental and physical constructions. Therefore, these constructions shape the persons' perception, as well as the activity that takes place within the social world, and become, in this way, engendered building structures; they are also objectified within social relations, which are, in turn, engendered, structured, and organized, both on a practical and on a semantic level, according to the socially and internally-incorporated gender-related mental and physical models.

The function of the rationale behind (gender) dominance is oriented towards the instillation, through the living experience that results from social relations, of those particular predispositions that correspond to the regulatory definitions and distinctions that apply to (gender) identity, and meet, or fail to meet, the socially-constructed collective expectations from the carrier of the identity and the role in question. In this way, it is possible for them to organize, both on differential and hierarchical grounds, the relations that exist between the subjects and their legitimized identities (as males and females), as well as the relations that determine these categories internally, based on the degree of realization of the validated social identity in practice, and naturally, on the relations between the aforementioned, and those persons who demonstrate a significant divergence from the socially legitimized and validated identities. Therefore, rather than considering any diversions from the officially regulated standards, as negations of the rule and examples that prove the rule false, by conceiving, in terms of hierarchy, constructions that further strengthen and support the rule, and provide orientation, largely by adopting a common approach, the actions of both the dominant and dominated groups may also serve as a basis for their ongoing degradation and exclusion.

Butler (2004), by attempting to draw upon a perspective of a more radical post-structural approach, criticizes earlier constructivist conceptualizations that refer to the gender, and to a larger extent, some of the variations of the constructivist point of view, from which these conceptualizations are derived. This form of criticism is consistent with the corresponding critical approach (combined with a touch of creative synthesis) that is expressed by Bourdieu on the two opposing, yet scientifically supplementary, ways of world-learning, i.e. subjectivism and objectivism. The theory of performativity does not view the subject 
exclusively in the light of a person that invokes the subjective gender identity, and as a factor that either precedes (as a cause) or follows (as an effect) the construction in terms of time. It rather views it as a key reference point that shifts towards temporarity, and the time dimension of the construction itself, which is thought of as process, within and through which the composition, production, and emergence of the subject take place, and which is clearly defined in the historical, cultural, and political terms that comprise the conditions, under which the subject is formed, and also set out the possibilities and the manner that stipulate its existence.

By conducting an investigation on the relationship between the material nature of the body, i.e. the body differences between "males" and "females" that are taken for granted, and the performativity of the gender, Butler - in agreement with Bourdieu - highlights the fact that there is not any specific pre-language or pre-social reality, in the form of an "object" that is completely "clear" and independent of the classifications, within which it is perceived, as well as the discursive practices that define and signify it.

The gender, therefore, is an arbitrary cultural convention - a culturally-determined construction - through the specific demarcation and pertinent social use of which, it becomes regulatory, since it defines and generates a number of inclusions and exclusions, and comprises a system of awareness and corresponding action. As a result, it possesses regulatory force, and this force can "produce", i.e. demarcate, differentiate, circulate, and signify the bodies that are under its control. Through this regulatory and exclusive demarcation, the realization and performativity practices themselves, by which it is reconfirmed, are defined, and therefore enforced by the regulatory framework, in a very specific manner.

Thus, Butler (similarly to Bourdieu) believes that the subjects become themselves accomplices in their submission, since they are constructed as such, and obtain their Entity, through an imposed reference and reconfirmation enforced by authority, as a result that is produced by the authority itself. As a resistance policy, according to her point of view, is recommended to adopt a policy that is not oriented towards identity, but rather towards its rejection (disassociation), and utilization of the inevitable instability of the regulatory example - which serves as a condition for the application of a method to compose identity - as a resource that contributes towards a symbolic fight to define the bodies that matter, and which namely refers to value, as these bodies are socially recognized and symbolically validated as legitimate representations and realizations of the "human".

The concept of spatiality, as a tool of analysis, enables multiple interpretations of the idea of sexuality; on top of that, when sexuality is used as a tool of analysis itself, it can shape time eternally, always under the perspective of the time dimension that refers to each historical framework. 
According to Venetia Kantsa (2010), "since it is socially constructed, in addition to being engendered, space is sexualized as well, while both the gender and sexuality are constructed with reference to the space."

Another dividing distinction that is generated by the dipolar concept of "Public-Private space" is that, in addition to the fact that the private space is identified with the female, while the public space with the male, which represents a patriarchal and capitalistic ideology at the same time, there is also the view, according to which, the private space offers the opportunity for a healthy and safe manifestation of sexuality, whereas the public space plays, literally, the role of hosting forms of delinquent sexual behavior. Using parallelism, it could be said that nowadays, the Public space is identified with the two dominant genders, and is the place where the expression of heterosexual relationships is permitted, while other sexually marginalized gender groups are restricted to the Private space (Sarigiannaki, 2012-2013).

Table of relative frequencies

\section{"EYDOKIA'S ZEIBEKIKO" CODES}

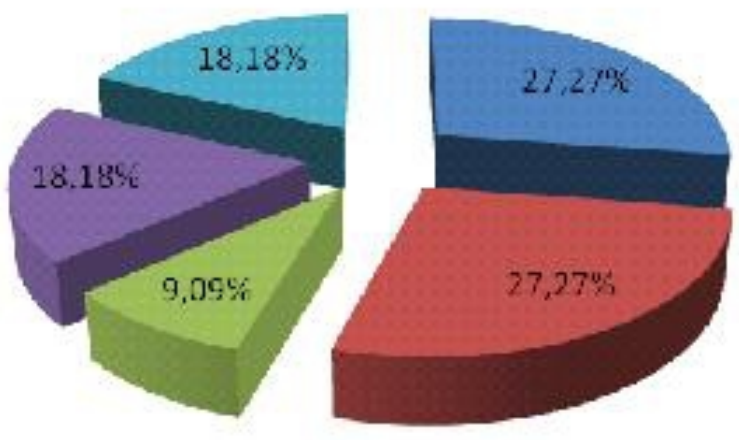

E GENDERCODE

$=$ SOCLALCODE

I SPAIIAL CODE

a SYMBOLICCODE

WALUECODE

Graphical representation

\section{Discussion}

The gender-related practices that are demonstrated through the viewing of and listening to activities, such as dance and music, are born under specific conditions. They do not result purely from habit, but they are generated through the interaction that takes place between habits and predispositions, with the specific setting in question, under the conditions, or within the fields, in which individuals act, or the "marketplace", within which they move, and the "social games", in which they participate. Each 
field is regarded as a structured and regulated transactional space. This means that the "positions" that compose it, combined with their hierarchical associations - which are relationships based on power and authority - are regulated by the allocated use of the specific, each time, "capital", in conjunction with the particular means, resource, or qualification that may apply to each field.

In addition to the economic capital, individuals deal with the "cultural capital" (acquired knowledge, skills, "education"), the "symbolic capital" (prestige), and the "language capital" in carrying out their transactions. Besides, a number of fields facilitate the conversion from one form of capital to the other; education, for example, provides cultural capital and prestige, which can secure a well-paid job.

The Modern Greek culture is representative of a Mediterranean cultural model, which is clearly distinguished from both the Western urban model and the traditional Eastern one.

Therefore, in an attempt to investigate the relationship that governs the characteristic features that are reflected in the bouzouki, as a musical instrument, through a representative sample of the zeibekiko dance, as it is displayed in the homonymous film, the following conclusions were drawn, after conducting a semiotic analysis: the visual analysis of the pictures resulted in a number of codes, such as the social, gender, value, symbolic, and spatial ones. More specifically, as a result of the visual analysis, according to their incidence rates, the codes were characterized by the following percentage rates: social code with a rate of $27.27 \%$, gender code with a rate of $27.27 \%$, value code with a rate of $18.18 \%$, symbolic code with a rate of $18.18 \%$, and spatial code with a rate of $9.09 \%$.

The key findings from the above analyses refer to the emerging masculinity of the dancer, the loneliness that characterizes the dance, and the values and respect shown to codes of honor, which confirms the initial literature research conducted on the zeibekiko dance, and by a further extent, the fact that the bouzouki expresses all the above characteristic features.

Furthermore, the identification and analysis of the cultural structures have resulted in the emergence of a number of dominant trends, which compose the special typological characteristics of the Modern Greek culture. These characteristics refer to the equivalence between nature and culture and between natural and ethical values (nature=culture), the identity relationship that links beauty and goodness (beauty=goodness), the simultaneous existence of rationalism and mysticism (rationalism+mysticism), and the synthesis of the individual and social perspective of things (individual + society=individual's perception). The resulting overall isotopy from the above conclusions is a dominant trend that is manifested in the synthesis and harmonization of contradictory concepts and ideas. 
Finally, a restrictive factor that did not facilitate the widespread promotion and great commercial success of the movie, as well as of the song, was the era, in which it was created and played, i.e. in 1971, when the director was sentenced by the colonels' junta, on the grounds that he offended the values of the Greek army. Recognition for the significance of the work for the bouzouki and the zeibekiko dance, as well as an identification of the music as another national anthem, was awarded much later. The words of Manos Loizos may disclose the hidden recipe for the classical, now, hit of Evdokia's Zeibekiko, which is that, when the zeibekiko and "hasapiko" dances are played with the chords and strings of the folk instruments, they generate a blissful emotion that is recognized as a form of pure folk expression.

Evdokia's Zeibekiko has resisted, so far, strongly against the modernday "sirens" of the music creation industry, as an authentic and unspoilt folk creation, with the bouzouki playing a key dominant role in it.

That is probably the reason why it has also dominated the mind of the majority of the Greek people, who have identified the bouzouki with Evdokia's Zeibekiko.

\section{References:}

1. Anogeianakis, F. (1991). Greek Folk Music Instruments. Athens. Melissa.

2. Valoukos, S. (1998). Filmography of the Greek Cinema (1914-1998). Athens. Aigokeros.

3. Gionis, D. (2014). La crème de la crème...A CLOSER LOOK ON 46+1 ART PERSONALITIES. Athens. AGYRA.

4. Damianakos, S. (2001). Sociology of rebetiko. Athens. Plethron.

5. Dragoumis, M. (1984). A musicological approach of rebetiko. Greek Culture Issues I. Athens.

6. Zolotas, X. (1997). Monetary and Economic studies 1945-1996, vol. $B$ '. Athens. Bank of Greece.

7. Kantsa V. (2010). Walking hugged in the streets of Athens: Samegender Sexualities in Urban Settings. Disputed Areas: Spatial approaches to Culture. (ed. Giannakopoulos K. and Giannitsiotis G.). Athens. Alexandreia.

8. Kapsomenos, E. (2005). "Towards a semiotics of the Modern Greek culture", Setting and development. Dialectic relationships and interdisciplinary approaches. (ed. Rokos, D). Athens. Enallaktikes Ekdoseis.

9. Konstantinidou, M. (1994). Sociological history of rebetiko. Athens. SELAS. 
10. Lagopoulos, A.F. \& Boklund-Lagopoulou, K. (2016). Semiotic Theory. The tradition of Ferdinand de Saussure. Athens. Patakis Publications.

11. Leousi, L. (2003). History of Greek Music 2000B.C.-2000A.D. Athens. Agyra.

12. Mazaraki, D. (1985). The folk clarinet in Greece. Athens. Kedros.

13. Boklund-Lagopoulou, K. (1983). What is semiotics? Diavazo (special edition on Semiotics) http://semiotics.nured.uowm.gr/pdfs/LAGOPOULOS_THEORY_SE MIOTICS.pdf

14. Moisiadis, P. (1986). Greek dances from Thrace. Thessaloniki. "DIOSKOUROI".

15. Palis, A. (1941). Pages from old Janissary Turkey. Athens. Ekati.

16. Papadopoulos, L. (2000). Manos Loizos. Athens. Kaktos.

17. Petropoulos, H. (1979). Rebetic songs. Athens. Kedros.

18. Sarigiannaki, D. (2012). Urban Space and Sexuality in the Western world during the $19^{\text {th }}$ century: From segregated realms to the sexualized space, $1^{\text {st }}$ Semester Assignment 2012-2013, Tutor: Giannis Giannitsiotis, University of the Aegean, "Females and genders: Anthropological and historical approaches" Postgraduate Studies Program".

19. Sotiropoulos, C. (1984). Diaspora in the Greek Cinema. Athens. Ypsilon.

20. Tyrovolas, V. (1992). Greek traditional dancing rhythms. Athens. Gutenberg.

21. Tyrovolas, V. (2003). Greek urban folk dances in Gyftoulas N. Et al., An overview of the Greek music and dance. Patra. Hellenic Open University (EAP).

22. Chalavelaki, M. (2010). An introduction to semiotics: Theory and applications. Athens. Kastaniotis.

23. Christodoulou, A. (2003). Semiotic analysis and culture in a foreign language. Semiotic analysis of learning material in a foreign language. The presentation of cultural characteristics in Italian language textbooks. Thessaloniki. University Studio Press.

24. Christodoulou, A. (2007). Semiotics and school textbooks. Thessaloniki. University Studio Press.

25. Christodoulou, A. (2012). Education, Training, Values: A Semiotic Approach. Thessaloniki. University Studio Press.

26. Baud-Bovy, S. (1984). An essay on the Greek folk song. Nafplio. Peloponnesian Folklore Foundation.

27. Barthes, R. (1988). Image-Music-Text (tr. Spanos, G.). Athens. Plethron. 
28. Barthes, R. (2007). Image-Music-Text ( ${ }^{\text {rd }}$ ed.). Athens. Plethron.

29. Bourdieu, P. (2006). The Logic of Practice. (tr.-ed. Paradellis, T). Athens. Alexandreia.

30. Bourdieu, P. (2007). Masculine domination. (tr. Giannopoulou, E.). Athens. Pataki.

31. Butler, J. (2004). Meaningful bodies: On the limitations of the 'gender' on speech level, The body's limits: Interdisciplinary approaches. (ed. Makrynioti, D.). Athens. Nisos.

32. Greimas, A-J. (1966). Semantique structurale. Richerche de methode. Paris. Larousse.

33. Greimas, A-J. (1968). Semantica Strutturale. Ricerca di metodo. (Traduzione dal Francese di I. sordid). Milano. Rizzoli.

34. Petridis, T. (1980). Greek dances. Athens. Lycabettus Press.

35. Tyrovolas, V. (1994). The evolutionary process of the dynamics of popular urban culture. The case of Zebekiko dance, Proceedings of the 17th Symposium of the Study Group of Ethoarchaeology. Nafplio.

\section{Webpages/websites}

36. Akrivou, I. (2011). 40 years since Evdokia's zeibekiko. Espresso. Retrieved on 25/9/2016, from http://www.espressonews.gr/\%CF\%80\%CE\%B5\%CF\%81\%CE\%B9 $\%$ СЕ\%В5\%СF\% 87\%СF\%8С\%СЕ\%ВC\%СЕ\%В5\%СЕ\%ВD\%СЕ\% $\mathrm{BF} / 54258 / 40-$

$\% \mathrm{CF} \% 87 \% \mathrm{CF} \% 81 \% \mathrm{CF} \% 8 \mathrm{C} \% \mathrm{CE} \% \mathrm{BD} \% \mathrm{CE} \% \mathrm{~B} 9 \% \mathrm{CE} \% \mathrm{~B} 1-$ $\% \mathrm{CE} \% \mathrm{~B} 1 \% \mathrm{CF} \% 80 \% \mathrm{CF} \% 8 \mathrm{C}-\% \mathrm{CF} \% 84 \% \mathrm{CE} \% \mathrm{BF}-$

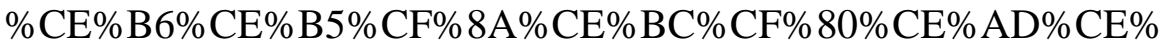

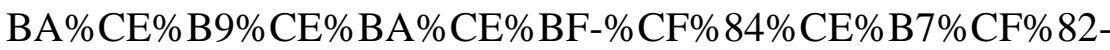

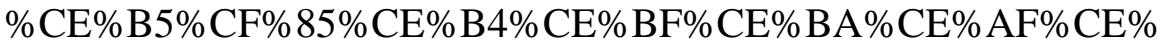
$\mathrm{B} 1 \% \mathrm{CF} \% 82$

37. Boskoitis, A. (2015). On Evdokia's Zeibekiko, by Manos Loizos. Lifo. Retrieved on 25/9/2016, from http://www.lifo.gr/team/music/54553

38. Paridis, C. (2015). Giorgos Koutouzis, the sergeant of "Evdokia", narrates how the legendary film directed by Damianos was filmed. Lifo. Retrieved on 25/9/2016, from http://www.lifo.gr/articles/cinema_articles/80999

39. Roussos, G. (2016). Ten years without the great Greek cinematographer, Alexis Damianos. Tvxs. Retrieved on 25/9/2016, from http://tvxs.gr/news/sinema/deka-xronia-xoris-ton-spoydaioellina-kinimatografisti-aleksi-damiano

40. Stathakopoulos, D. A "SHORT DISCOURSE" ON THE BOUZOUKI", retrieved on 4/9/2017, http://www.palaixthon.gr/2013/04/\%CF\%80\%CE\%B1\%CE\%BD\%C 
Е\%B4\%CE\%BF\%CF\% 85\%CF\%81\%CE\%AF\%CF\%82$\% \mathrm{CF} \% 84 \% \mathrm{CE} \% \mathrm{~B} 1 \% \mathrm{CE} \% \mathrm{BC} \% \mathrm{CF} \% 80 \% \mathrm{CE} \% \mathrm{BF} \% \mathrm{CF} \% 85 \% \mathrm{CF} \% 8$ $1 \% \mathrm{CE} \% \mathrm{AC} \% \mathrm{CF} \% 82-$

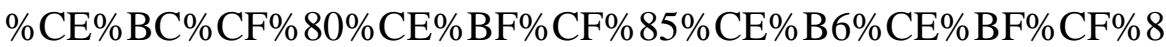
D\%CE\%BA\%CE\%B9-\%CF\%84\%CE\%BF-\%CE\%B1\%CE\%BD/

\section{Citation}

In the following picture we see a bouzouki image. A recording of Evdokia's Zeibekiko by the researcher who conducted the assignment will follow, in sheet music for bouzouki.

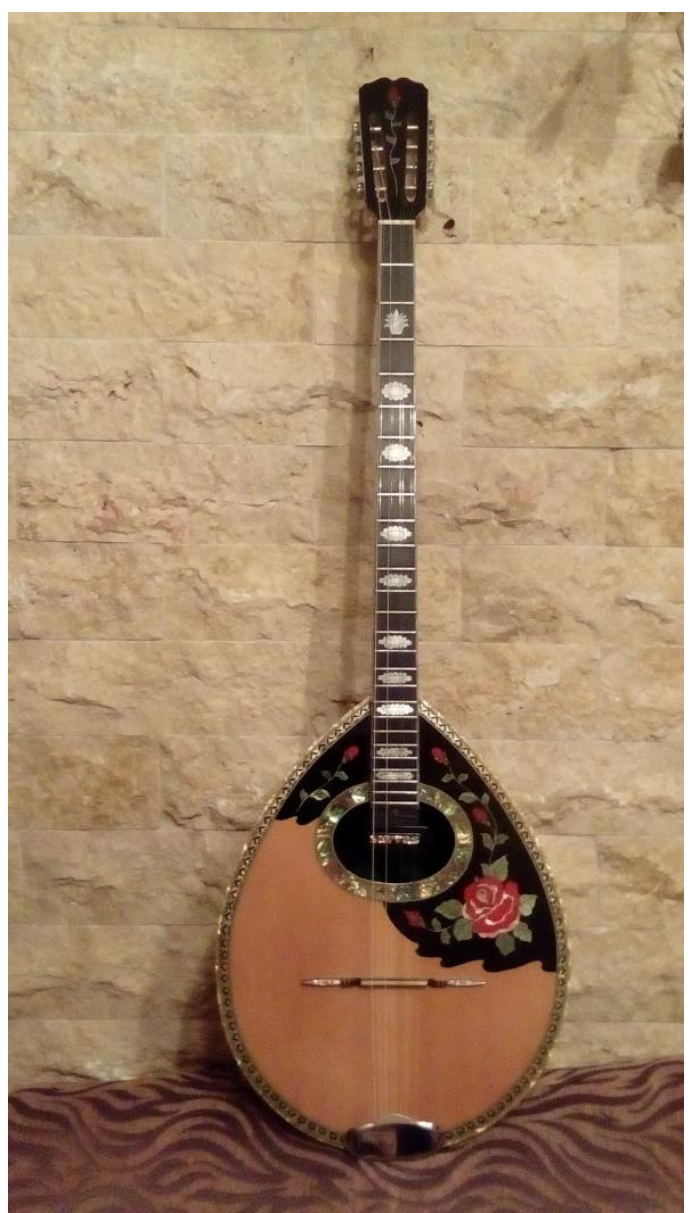

Bouzouki 


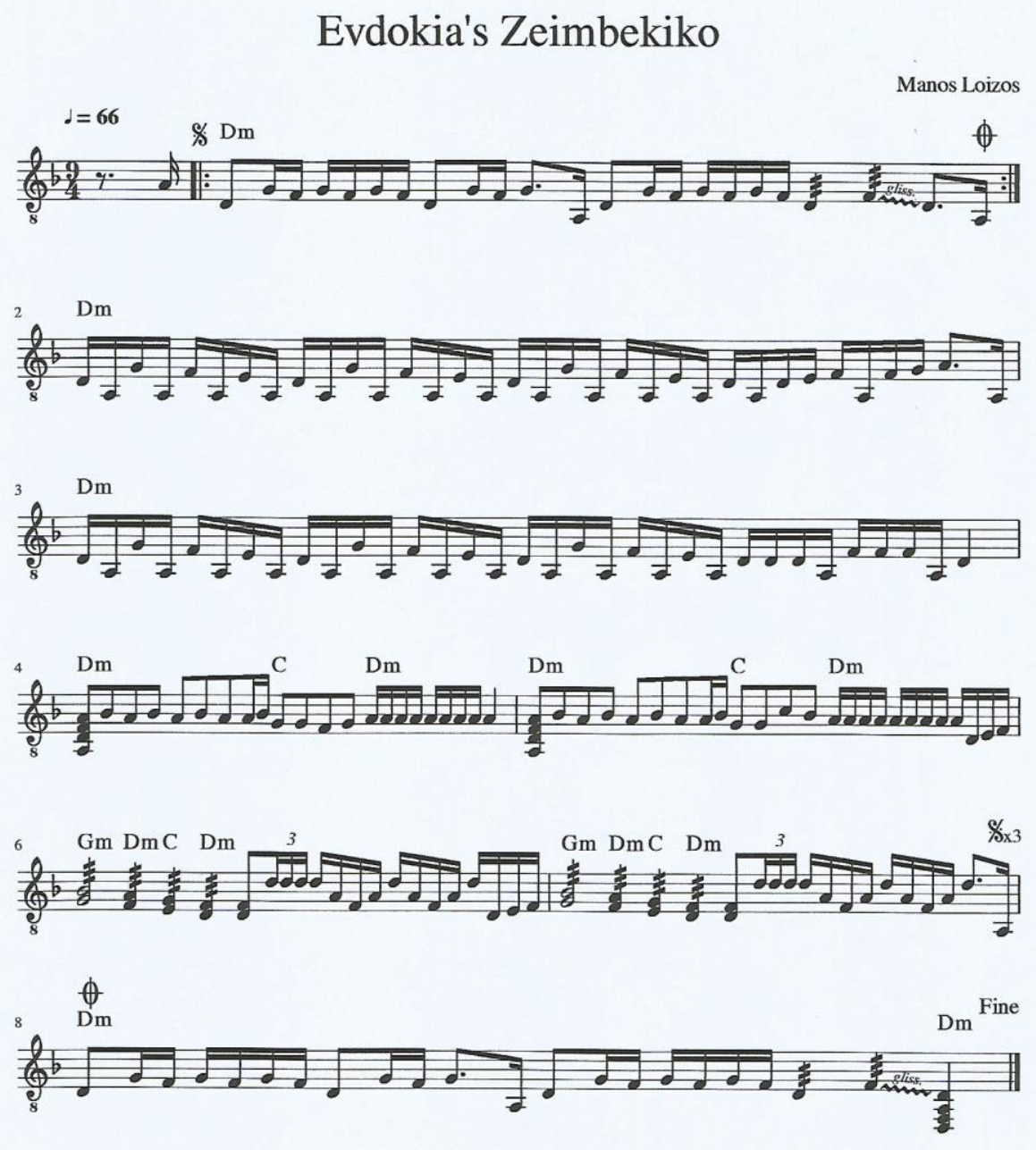

Saragatsis Evangelos 